\title{
DRUMMOND, TRADUTOR DE LES LIAISONS DANGEREUSES
}

Marlova Aseff*

\begin{abstract}
RESUMO: Este estudo busca analisar a tradução para o português de uma obra relevante da literatura mundial As relações perigosas, de Choderlos de Laclos (1741-1803) - centrando-se em dois pontos: seu tradutor, Carlos Drummond de Andrade, e nos possiveis ecos dessa tradução na obra de Drummod, que foi um dos mais importantes poetas brasileiros. Também lançaremos mão da tradução feita por Sérgio Milliet, poeta e ensaísta ligado ao movimento modernista de 1922, não para fazer juízos de valor, mas para melhor visualizar as habilidades e as escolhas de Drummond enquanto tradutor. ${ }^{1}$
\end{abstract}

UNITERMOS: tradução literária; Carlos Drummond de Andrade; Sérgio Milliet; Choderlos de Laclos.

ABSTRACT: This article intends to analyze the Portuguese translation of a literary work of worldwide relevance, namely Dangerous Liaisons by Choderlos de Laclos (1741-1803). Two aspects will be focused on: the translator, Carlos Drummond de Andrade, and the possible resonance of the translation in his own work as one of the most important

* Universidade Federal de Santa Catarina (UFSC).

1 Este estudo não tem por objetivo cotejar a tradução com o original. Esta proposta foi levada a cabo na disciplina "Ficção traduzida por escritores brasileiros", do curso de Pós-Graduação em Literatura da UFSC, cujos objetivos eram: a) analisar uma tradução literária elaborada por escritor brasileiro; b) situar a literatura traduzida no sistema literário nacional (reforço e renovação do cânone, introdução de novos gêneros e tendências, importação de temas e de procedimentos, etc); c) estabelecer relações entre obra traduzida e obra própria; d) reler a história da literatura brasileira a partir da literatura traduzida.

TradTerm, 11, 2005, p. 189-199 
Brazilian poets. We will also resort to the translation issued by Sérgio Milliet, a poet and essayist connected to the Brazilian modernist movement of 1922. The purpose of this is to gain a clearer perspective on Drummond's abilities and choices as a translator, while avoiding any judgmental comparisons.

KEYWORDS: literary translation, Carlos Drummond de Andrade, Sérgio Milliet, Choderlos de Laclos

\section{1 - O que levou Drummond a traduzir As relações perigosas?}

Para Antoine Berman, "uma das tarefas de uma hermenêutica do traduzir é apreciá-la tendo em vista o sujeito que traduz" (Berman, 1995: 73). ${ }^{2}$ Responder à questão "quem é o tradutor?" é importante porque pode fornecer as pistas necessárias para se descobrir, sobre o tradutor: a) sua posição tradutiva; b) seu projeto de tradução; e c) seu horizonte tradutivo. A posição tradutiva é o "compromisso entre a maneira na qual o tradutor toma consciência enquanto sujeito preso à pulsão de traduzir, a tarefa da tradução e a maneira como ele internalizou o discurso do meio sobre o traduzir" (Berman, 1995: 75).

José Maria Cançado, jornalista e autor da biografia de Drummond Os Sapatos de Orfeu, revela que a tradução de As relações perigosas não foi uma encomenda da editora. Drummond teria traduzido o romance epistolar pelo desafio e por ser esse um de seus livros preferidos. Cançado afirma que "numa dessas listas de dez mais, Drummond colocara esse romance no alto". ${ }^{3}$ As informações de Cançado dão conta que Drummond traduziu o romance em 1943. No entanto, a publicação ocorreu somente em 1947, na coleção "Grandes Romances", da editora Globo, dirigida por Paulo Rónai. Ainda segundo Cançado, a última tradução que Drummond fez (Fome, do sueco Knut Hamsun, de 1963) também teria sido motivada pelo desafio. Aí já temos

\footnotetext{
2 As citações de Berman 1995 são traduções minhas.

3 Ver Folha de São Paulo, Caderno Mais, 27/10/2002.
} 
uma pista da posição tradutiva de Drummond: a admiração pelos textos que escolhia e o desafio de realizar a tarefa.

Aparentemente, a atividade do poeta como tradutor durou 20 anos - de 1943 a 1963 - período no qual traduziu nove títulos. Ou seja, foi bem menos produtivo do que seu colega Mario Quintana, que traduziu algo em torno de trinta obras entre 1934 e 1955. Em ordem cronológica, estas foram as obras e os poemas traduzidos pelo mineiro: Uma gota de veneno (Therèse Desqueyroux), de François Mauriac (1943); As Relações Perigosas, de Choderlos de Laclos (1947); Os Camponeses, de Honoré de Balzac, que faz parte de A Comédia Humana (1954). Em 1955, aparecem poemas traduzidos por Drummond na antologia Obrasprimas da poesia universal, editada pela Livraria Martins Editora, com organização, seleção e nota bibliográficas de Sérgio Milliet. São eles: "A aldeia escuta", de Jacques Prévert, "A virgem ao meio-dia" e "O crucifixo", ambos de Paul Claudel, "A casada infiel”, de Federico García Lorca, "Um único pensamento", de Paul Éluard, tradução conjunta com Manuel Bandeira. Em 1956, traduz A Fugitiva (Albertine disparue), de Marcel Proust, em 1959, Dona Rosita, a solteira, teatro em verso de Federico Garcia Lorca, em 1960, Beija-Flores do Brasil, ensaio de Th.Descourtilz, em 1962, O pássaro azul, de Maurice Maeterlink, em 1962, Artimanhas de Scarpino, de Molière e, em 1963, Fome, de Knut Hamsum. Vê-se que também seu projeto de tradução teria sido movido por interesses pessoais.

Quanto ao horizonte da tradução de Drummond, qualificado por Berman como o conjunto dos parâmetros da linguagem, literários, culturais e históricos que 'determinam'o sentir, o agir e o pensar de um tradutor, é importante levar em conta o movimento modernista. Nelson Werneck Sodré situa Drummond na segunda fase do Modernismo, que se inicia em 1930. Para ele, o que caracterizaria esse período seria a tônica no conteúdo, ao contrário da primeira fase, cuja ênfase fora colocada na forma. Sodré acredita que a linguagem, após 1930, perdeu muito de sua beleza, originalidade e flexibilidade: Drummond configuraria uma exceção (Sodré, 1995: 545-548).

As marcas do modernismo estariam no horizonte das traduções do poeta, principalmente no tipo de linguagem que vai 
priorizar (irônica e coloquial), ou mesmo pelo tratamento dado a temas vislumbrados simultaneamente na tradução de As relações perigosas e em sua própria poesia. Isso ficará mais claro adiante, quando analisarmos a tradução propriamente dita.

\section{2-O fascinio de As relações perigosas sobre Drummond}

Em As relações perigosas, Visconde de Valmont e Madame de Merteuil jogam inescrupulosamente com as vidas de "inocentes úteis". Tudo em nome de seus interesses particulares e mesquinhos: ela quer vingar-se de um antigo amante; ele quer o prazer de mais uma conquista para enriquecer seu currículo de libertino. Na verdade, eles amam o jogo da sedução. Para isso, desenganam uma adolescente ingênua e levam ao adultério e, em seguida, ao desvario uma mulher de sentimentos puros. Por meio dos ardis de tais protagonistas, Laclos revela o vazio da classe social à qual pertencem, ou seja, a aristocracia às vésperas da Revolução Francesa. É o próprio Drummond que demonstra seu fascínio pelo romance no posfácio da edição da Globo. O poeta disserta sobre o clima nos salões franceses da segunda metade do século 18, ambiente freqüentado por Laclos.

(Os salões), com suas últimas preciosas, seus tolos e seus filósofos, seu pré-romantismo, numa agitação de aparência inconseqüente mas que trazia a fase final de decomposição de uma classe e a inexorável ascensão de outra (Andrade, 1987: 384).

Sua análise traz a leitura politica que marca seus primeiros trabalhos como poeta: Alguma poesia, Brejo das almas, Sentimento do mundo e A rosa do povo. Drummond parece compartilhar com Laclos o gosto pela denúncia. Conforme John Gledson, o poeta era um rebelde. "Ele gostava às vezes de constranger, gostava de chocar".

4 Revista Cult, novembro de 2003. 
Drummond destaca a "veia poética mundana e repentista" de Laclos, misto de engenheiro militar e poeta de salão que usava "os versos para circular impunemente na sociedade" (Andrade, 1987: 387). No entanto, enquanto eram essas as suas atividades, ele não importunava. É interessante o trecho no qual Drummond exemplifica como a ironia ${ }^{5}$ - traço que também marcou sua própria poesia - opera na vida em sociedade:

Todos nós nos sentimos um pouco aliviados quando alguém a nosso lado ironiza o ridículo de nossos amigos ou de nossos conhecidos - pequenina vingança que tiramos pela fraqueza de os estimarmos tanto ou de os vermos a toda hora. E perfídias miúdas fazem parte da boa educação (Andrade, 1987: 388).

Enquanto eram apenas pequenas ironias, Laclos era bemvisto. Todavia, quando publica As relações perigosas, em 1782, "o desgosto e a surpresa são gerais". Para Drummond

O pecado não está nas palavras, que são sóbrias e mesmo castas (e como escrevia bem esse danado, em meio à incontinência verbal que teimava em subsistir ao lado da tradição de simplicidade e secura); nem propriamente na imprudência da ação (...). Está na intenção do autor, que nos convidou para um divertissement e nos oferece um espetáculo atroz em que o mais sujo e o mais imperdoável de nós mesmos é captado com solércia. Depõe contra as duas classes em luta, depõe contra o tempo, mas principalmente depõe contra a natureza humana. É um livro impossivel (Andrade, 1987: 389).

O embate, aqui polarizado entre "o mais sujo e imperdoável de nós” e a consciência, é uma das marcas da poesia de

5 Para Affonso Romano de Sant'Anna, “a ironia em Drummond obedece originalmente a um dos traços de sua personalidade (...) e, em segundo lugar, nos seus livros iniciais corresponde a um recurso, posto em voga durante os primeiros anos de Modernismo, através do qual se fazia a crítica e autocrítica de uma cultura". Ver Sant'Anna 1980: 60. 
Drummond. É Davi Arrigucci Jr. quem, no ensaio Coração Partido, sustenta que na obra de Drummond o conflito exerce um papel preponderante. Diz ele: "O poeta que surge em 1930 e acabou se tornando a figura emblemática da poesia moderna no Brasil construiu uma grande obra em que tudo acontece por conflito" (Arrigucci Jr., 2002: 152).

Drummond também fala sobre o tratamento do amor em Laclos, reflexão que adquire importância por ser essa outra temática importante da poética do mineiro. Ao combater o tipo de amor e de paixão apresentado no romance, por oposição, Drummond faz uma defesa do tipo de amor que considera verdadeiro e também dos sentimentos puros:

As relações não pintam a paixão, mas o fingimento dela, salvo no caso particular da Madame de Tourvel. Esta é, porém, uma figura que não aparece para legitimar a do verdadeiro amor, mesmo ilegal, e sim sua inanidade sem razão num mundo que os sentimentos mais poderosos são os falsificados (Andrade, 1987: 391).

Para o poeta, o amor é um sentimento que vai à procura do outro na relação. Não se resume à sedução ou ao desejo. Podemos perceber isso no trecho a seguir. Nele, Drummond qualifica As relações perigosas como um livro triste:

O livro se passa todo ele numa atmosfera de laboratório em que se exercitam um homem e uma mulher condenados por sua natureza a realizar até a morte experiências de sedução. Um livro álgido, um livro triste. Vaidade e desejo sexual, eis os dois únicos elementos desse jogo, observa André Malraux: vaidade contra vaidade, vaidade contra desejo, desejo contra vaidade (Andrade, 1987: 391392).

Para demonstrar como funcionavam as relações nesse grupo, em certa altura de seu posfácio, Drummond descreve figuras verídicas da sociedade francesa que freqüentavam os mesmos salões que Laclos: 
Era Madame du Deffand, já cega e idosa, amando com fúria o jovem Hugh Walpole e mantendo em torno de sua poltrona uma sociedade de céticos e de analistas. Era Mademoiselle de Lespinasse, amada por uns e amando outros, também com sua corte de espíritos fortes, merecendo ter sua casa chamada de "laboratório da Enciclopédia" (Andrade, 1987: 385).

Quando ele diz "dama era amada por uns enquanto amava outros", é impossivel não lembrar imediatamente de um dos mais difundidos poemas de Drummond, "Quadrilha" (do livro Alguma Poesia, 1930), que trata dos desencontros amorosos:

João amava Teresa que amava Raimundo que amava Maria que amava Joaquim que amava Lili que não amava ninguém.

João foi para os Estados Unidos, Teresa para o convento, Raimundo morreu de desastre, Maria ficou para tia, Joaquim suicidou-se e Lili casou com J. Pinto Fernandes que não tinha entrado na história.

\section{3 - O paratexto: edições populares e apelo comercial erótico}

Em Palimpsestes, Gerard Genette enumera os elementos que formam o "paratexto", um dos cinco tipos de relações transtextuais: títulos e subtítulos, intertítulos, prefácios e posfácios, advertências, notas, epígrafes, ilustrações, capa, orelhas. Enfim, tudo o que cerca o texto e por meio do qual o leitor pode inteirar-se de suas pretensões.

As duas edições de As relações perigosas que analisamos aqui são populares. ${ }^{6}$ A edição da Anima (originalmente Milliet traduziu para a Abril Cultural), é mais visivelmente de apelo popular. Traz na capa uma foto com duas mulheres vestidas com roupas dos anos 80 do século 20, de óculos escuros, bebendo vinho

6 Não foi possivel localizar as primeiras edições. 
numa espécie de salão de café. Uma delas tem um seio desnudo. A impressão é a de que temos em mãos um best-seller picante. Já a edição da Globo mostra detalhe do quadro "Vênus e amor", óleo de Lucas de Cranach, pintor renascentista alemão que costumava pintar nus míticos e sensuais. O traço comum é que ela também tem os seios desnudos. Ou seja, ambas as edições querem vender uma certa idéia de erotismo na capa dos livros. A editora Globo o faz de forma menos apelativa do que a Anima.

Nesta última não consta a data de publicação. Apenas o título, o nome do tradutor e do autor aparecem na primeira página e parte do título original é mencionado na página dois. $\mathrm{O}$ livro abre com a biografia não assinada de Choderlos de Laclos. Não sabemos se foi Milliet quem a escreveu. Não há referências à biografia de Milliet, poeta e ensaísta, tradutor de romances de Simone de Beauvoir e de André Gide, entre outros.

A edição da Globo analisada, em papel jornal, é de 1987. Consta que é a segunda edição. Outro detalhe é que a edição da Globo traz um subtítulo à obra: As relações perigosas ou cartas recolhidas num meio social e publicadas para o ensinamento de outros. O nome de Drummond como tradutor aparece com destaque na página quatro, mas não é mencionado na capa nem na contracapa. Essa edição conta ainda com sumário (dispensado na edição da Anima), com posfácio do tradutor e cronologia da vida do autor. Na edição da Anima, a contracapa é utilizada para fazer propaganda de outros lançamentos da editora; já na da Globo, há um pequeno texto situando o leitor acerca da importância do romance.

A Anima cumpre esse papel informativo nas orelhas do livro. A epígrafe de Rousseau, que está traduzida na versão de Drummond, permanece em francês na tradução de Milliet. Conforme alerta Berman, essa é uma incongruência do projeto: trata-se da edição popular de um texto traduzido, mas não se leva em conta que a maioria dos leitores não seja capaz de ler em francês.

\section{4 - Análise das traduções de Drummond e de Milliet}

Na opinião de Cançado, a tradução feita por Drummond de As relações perigosas é "primorosa, melhor do que as outras 
duas que também circularam no Brasil - a de Osório Borba e a de Sérgio Milliet". Entretanto, nosso propósito não é fazer uma avaliação qualitativa. Vamos comparar trechos da tradução de Milliet e de Drummond, não com o intuito de fazer juízo de valor, mas para analisar diferenças de linguagem e escolhas.

É importante ressaltar, antes, que se percebe, na tradução de Drummond, uma busca efetiva pela linguagem coloquial e pela concisão. Nessa época, sua poesia, apesar de conter traços coloquiais, observava a norma culta. "Sua lírica é impura até certo ponto, mais no sentido de busca de uma clareza próxima da prosa". ${ }^{7}$

Quanto ao uso de uma linguagem mais próxima da fala cotidiana, Drummond demonstra essa preocupação quando, por exemplo, na carta 101, na qual Valmont repreende seu criado, escolhe a segunda pessoa do singular, ao passo que Milliet usa a segunda pessoa do plural:

É preciso que sejais muito imbecil, tendo partido daqui esta manhã, para não saberdes que a Sra.de Tourvel também partira. Ou, se o sabíeis, para não me terdes avisado.(Milliet)
É preciso que sejas bastante imbecil, tu que partiste esta manhã, para não saberes que Madame de Tourvel partiu também; ou, se o sabias, para não me teres avisado. (Drummond)

O cuidado com o estilo fica demonstrado em sua preocupação em não repetir palavras, como na carta 44, ou de economizar palavras, como nos exemplos das cartas 4 e 6 . Na carta 4, entretanto, ambos os tradutores produzem uma cacofonia (segundo quadro):

Compartilhai minha alegria, minha bela Compartilhai minha alegria, bela amiga: sou amiga: sou amado, triunfei sobre o coração amado, triunfei sobre aquele coração rebelde. rebelde. (Milliet, carta 44) (Drummond, carta 44)

\begin{tabular}{|lll|l|l|}
\hline Vossas ordens são encantadoras, vossa & Vossas ordens são encantadoras; a maneira de \\
\hline
\end{tabular} maneira de dá-las é mais amável ainda; faríeis dá-las é mais amável ainda. Tornaríeis com que se adorasse o próprio despotismo. adorável o próprio despotismo. (Drummond, (Milliet, carta 4) carta 4)

\begin{tabular}{|l|l|l}
\hline Mas que digo? Terá ela a necessidade de & Mas que digo? Madame de Tourvel precisará
\end{tabular} ilusão? (Milliet, carta 6) de ilusão? (Drummond, carta 6)

$7 \quad$ Uma poética do riso, p. 110. 
Outro aspecto interessante é a diferença de ritmo, como nesta passagem irônica na qual Madame Merteuil escreve à jovem Cécile Volanges. Observe-se como pequenos detalhes fazem diferença na leitura do texto:

\begin{tabular}{|l|l|}
\hline Então, menina, eis-vos muito aborrecida e & Então, pequena, por que ficar tão irritada e \\
muito envergonhada! E esse Sr. de Valmont é & envergonhada? Esse Sr. de Valmont é um \\
um homem muito mau, não é? Pois não ousa & homem perverso, não é? Como! Ele ousa \\
tratar-vos como a mulher que mais amasse? & tratar-vos como a mulher a quem mais ama! \\
Ele vos ensina o que morríeis de vontade de & Ensina o que morríeis de desejo por saber! De \\
saber! Em verdade, tais procedimentos são & fato, seu procedimento é imperdoável. E, por \\
imperdoáveis. E vós, por vosso lado, quereis & vosso lado, quereis guardar a virtude para o \\
guardar vossa virtude para o vosso amado & vosso amado (que dela não abusa), só \\
(que não abusa dela), e só adorais no amor as & apreciais no amor os pesares, não os prazeres. \\
tristezas, não os prazeres. (Milliet, carta 105) & (Drummond, carta 105) \\
\hline
\end{tabular}

No pequeno trecho selecionado, Milliet utiliza sete vezes os pronomes vós, vos e vosso. Já Drummond, com perspicácia de quem tem a palavra como matéria-prima, resume a três o uso dos mesmos pronomes, o que torna a leitura muito mais leve. Também a aliteração "pesares" versus "prazeres" é mais requintada e próxima da linguagem poética do que "tristezas" versus "prazeres". O uso do "Como!" na terceira linha do trecho traduzido por Drummond dá o tom irônico do parágrafo. Também a escolha do tempo do verbo amar, na quinta linha, parece mais acertada em Drummond do que em Milliet. Como foi dito, não é intenção fazer análise qualitativa, mas fica evidente a diferença de habilidade entre um tradutor e outro. Sobre o ato de simplificar a escrita, Drummond afirmou:

A medida que envelheço, vou me desfazendo dos adjetivos. Chego a crer que tudo se pode dizer sem eles. Por que "noite gélida", "noite solitária", "profunda noite"? Basta "a noite". O frio, a solidão, a profundidade da noite estão latentes no leitor, prestes a envolvê-lo, à simples evocação da palavra noite (Drummond apud Santiago, 1976: 116).

\section{5 - Conclusão}

Drummond vê no romance de Laclos temas e conflitos que lhe atraem profundamente enquanto indivíduo, tanto que muitos 
deles serão uma constante em sua obra, como o desencontro, o amor, a ironia no trato social. Por isso, traduz o livro por iniciativa própria: o que o impulsiona é o fascínio que a obra lhe provoca.

Também a linguagem de Laclos o interessa e parece adequar-se a seu projeto pessoal, influenciado pelo modernismo. Quando afirma: "como escrevia bem esse danado, em meio à incontinência verbal que teimava em subsistir ao lado da tradição de simplicidade e secura", Drummond, em conseqüência, revela seu ideal estético: uma linguagem concisa, mas que não se empobrece com isso.

\section{6 - Bibliografia}

ANDRADE, Carlos Drummond de. (1987) "Posfácio do tradutor". In: As relações Perigosas. Rio de Janeiro: Globo.

ARRIGUCCI Jr., Davi. (2002) Coração Partido. São Paulo: Cosac \& Naify. BERMAN, Antoine. (1995) Pour une critique des traductions: John Donne. Paris: Gallimard.

CANÇADO, José Maria. (2002) "Uma experiência atroz". Caderno Mais, Folha de São Paulo. São Paulo, 27/10, p. 11.

GENETTE, Gerard. (1982) Palimpsestes: la littérature au second degré. Paris: Éditions du Seuil.

GLEDSON, John. (2003) "O Sherlock da crítica”. Entrevista a Carlos Eduardo Ortolan Miranda. Revista Cult, São Paulo, novembro, pp. 26-31.

LACLOS, Choderlos de. As relações perigosas. Tradução de Carlos Drummond de Andrade. Rio de Janeiro: Globo, 1987.

. As ligações perigosas. Tradução de Sérgio Milliet. Rio de Janeiro: Anima, s/data.

MILliET, Sergio. Diário Crítico de Sérgio Milliet. 2. ed. São Paulo: Livraria Martins Editora, 1981.

SANT ANNA, Afonso Romano de. Carlos Drummond de Andrade: análise da obra. Rio de Janeiro: Nova Fronteira, 1980.

SANTIAGO, Silviano. Carlos Drummond de Andrade. Coleção Poetas do Brasil. Rio de janeiro: Vozes, 1976.

SIMON, Ilumna Maria. Drummond: uma poética do riso.São Paulo: Ática, 1978.

SODRÉ, Nelson Werneck. História da literatura brasileira. Rio de Janeiro: Bertrand Brasil, 1995. 